Submitted to Mind, Brain, and Education

June 30,2016

Effects of Prior Knowledge on Memory: Implications for Education

Yee Lee Shinga,b \& Garvin Broda

a Center for Lifespan Psychology, Max Planck Institute for Human Development, Berlin,

Germany

b Division of Psychology, School of Natural Sciences, University of Stirling, UK

\begin{abstract}
Author Note
YLS was financially supported by a Minerva Research Group of the Max Planck Society. We thank Julia Delius for her helpful comments and editorial assistance. Correspondence concerning this article should be addressed to Yee Lee Shing, Division of Psychology, School of Natural Sciences, University of Stirling, UK. Email: yee.shing@stir.ac.uk
\end{abstract}

This is the peer reviewed version of the following article: Shing, Y. L. and Brod, G. (2016), Effects of Prior Knowledge on Memory: Implications for Education. Mind, Brain, and Education, 10: 153-161. doi: 10.1111/mbe.12110, which has been published in final form at http://onlinelibrary.wiley.com/wol1/doi/10.1111/mbe.12110/full. This article may be used for non-commercial purposes in accordance With Wiley Terms and Conditions for self-archiving. 


\begin{abstract}
The encoding, consolidation, and retrieval of events and facts form the basis for acquiring new skills and knowledge. Prior knowledge can enhance those memory processes considerably and thus foster knowledge acquisition. But prior knowledge can also hinder knowledge acquisition, in particular when the to-be-learned information is inconsistent with the presuppositions of the learner. Therefore, taking students' prior knowledge into account and knowing about the way it affects memory processes is important for optimization of students' learning. Recent behavioral and neuroimaging experiments have shed new light on the neural mechanisms through which prior knowledge affects memory. However, relatively little is known about developmental differences in the ability to make efficient use of one's knowledge base for memory purposes. In this paper, we review and integrate recent empirical evidence from developmental psychology and cognitive neuroscience about the effects of prior knowledge on memory processes. In particular, this may entail an extended shift from processing in the medial temporal lobes of the brain towards processing in the neocortex. Such findings have implications for students as developing individuals. Therefore, we highlight recent insights from cognitive neuroscience that call for further investigation in educational settings, discussing to what extent these novel insights may inform teaching in the classroom.
\end{abstract}




\section{Effects of Prior Knowledge on Memory: Implications for Education}

Imagine the following scenario in a classroom: a science teacher is teaching a group of middle-school students how to derive the mechanical energy of a skier who is gliding down a hill. This lesson builds upon information from a previous lesson some days ago, in which the teacher presented the more basic concept of potential energy, that is, the energy resulting from an object's position. As the students should possess the necessary prior knowledge, the teacher goes ahead and presents the new information in this lesson, namely that the mechanical energy of an object can be calculated as the sum of its potential and kinetic energy. Unfortunately, the teacher later realizes that half of the students fail to solve a similar problem on mechanical energy. When probed for factual knowledge, they cannot even remember the individual elements in the equation needed to calculate total mechanical energy. While there may be many reasons why the students fail to attain a learning goal, we propose that one of the key players here is prior knowledge and its roles in learning and memorizing new information.

In this review, we provide a summary of our current understanding about the intersection between prior knowledge and memory processes. We focus on the neural mechanisms and developmental differences therein that may have implications for education. This is followed by some ideas that we regard as important for further consideration and empirical investigation within educational settings. In the following, we shall first provide a brief definition of prior knowledge. 


\section{A definition of prior knowledge}

Research that deals with the ways in which existing knowledge structures interact with new information has mostly used the term schema or prior knowledge to refer to those existing structures. Schema, which Piaget (1926) integrated into the field of developmental psychology, refers to a general cognitive structure that links multiple representations of a phenomenon. The existence of a schema may alter an individual's interpretation of new information, a notion that Piaget implied across multiple cognitive domains including perception. For the purpose of this paper, we adopt the framework of memory schemas by Ghosh and Gilboa (2014), which postulates that necessary schema features are (1) an associative network structure composed of units and their interrelationships, (2) based on multiple episodes, (3) a lack of unit details, and (4) adaptability. The second and third features follow from each other, suggesting that knowledge structures are general, higherlevel constructs that encompass representations of commonalities across events. Schemas are also adaptive in that they can store vast amounts of information derived from many experiences and can update that information in an environmentally sensitive manner.

The adaptability of schemas follows Piaget's concepts of accommodation and assimilation as complimentary processes that support individual's adaptation to the environment (Piaget, 1952). Accommodation is the process by which people update a schema when new information from the environment conflicts with existing knowledge, while assimilation is the process by which people integrate and subsume properties of the environment into their existing schemas. These ideas have been developed further in psychological and educational research. For example, Vosniadou and Brewer (1992) hypothesized that children's construction of a mental model is based on their observations 
and everyday cultural influences. The acquisition of a scientific model presumably involves a major conceptual reorganization that proceeds through the revision and rejection of children's presuppositions (Vosniadou et al., 2004).

Recognizing that conceptual change is a complex issue (e.g., see review by diSessa, 2006), our analysis in this paper focuses on the interactions between schemas, which we will refer to henceforth as prior knowledge, and memory processes, that is, encoding, consolidation, and retrieval of new information. These interactions may be more involved in the acquisition of factual knowledge (e.g., basic arithmetic) than in the revision of complex representation structures (see Carey, 2000 on conceptual growth vs. change), but they form the basis of the process of knowledge acquisition.

In the sections below, we review (1) work on the cognitive mechanisms underpinning the effects of prior knowledge on memory processing, and the developmental differences therein, (2) the more recent neuroscience literature on the effects of prior knowledge on memory networks as well as on consolidation or stabilization of memory representations, and (3) research on the developmental differences in neural correlates of memory networks in interaction with prior knowledge.

Cognitive mechanisms underlying the effects of prior knowledge on memory processing Extensive reviews of behavioral research about effects of prior knowledge on memory are available (Alba \& Hasher, 1983; Brod, Werkle-Bergner, \& Shing, 2013). We present here only the guiding principles from this literature. 
Principle 1. Prior knowledge facilitates memory for incoming information because it provides a structure into which the new information can be integrated (see also levels-ofprocessing framework proposed by Craik and Lockhart, 1972). This principle applies to various stages of memory processing, including encoding, consolidation, and retrieval. In a seminal review by Alba and Hasher (1983), the processes by which prior knowledge can influence memory have been identified as selection, abstraction, interpretation, integration, and reconstruction. The first four of these processes are suggested to influence encoding, whereas reconstruction influences retrieval. Selection refers to the notion that information that is most relevant to the currently active knowledge structures is paid more attention, leading to some items being remembered better than others. The process of abstraction suggests that the selected information is reduced such that details of the situation are not preserved, whereas interpretation means that additional information that was not present can be inferred based on knowledge about the situation. Information successfully passing through these three steps will be integrated into the individual's existing knowledge structures. To retrieve the information later on, it has to be reconstructed based on the integrated representation, and this process can be facilitated by the individual's knowledge about the retrieval context.

Principle 2. Knowledge needs to be activated appropriately to benefit memory processing of new information. In general, while there is compelling evidence for the notion that memory can be facilitated by prior knowledge, supporting the processes identified by Alba and Hasher (1983), it is also clear that possessing prior knowledge as such is not enough. It needs to be activated properly during encoding to facilitate creation of an elaborated memory trace (Bransford \& Johnson, 1972; Craik \& Tulving, 1975; see also 
Brod et al., 2013). Furthermore, the retrieval context plays an important role for successful recovery of a memory, because it has to (1) provide enough information to help reinstantiate the encoding context, and (2) match the target information well, for instance, via semantic congruency (Moscovitch \& Craik, 1976).

Taken together, one should not assume that the availability of knowledge automatically benefits memory processing of new information. If not accessed appropriately, a memory benefit due to prior knowledge is less likely. In the classroom example given above, the source of the problem might be that the students' prior knowledge was not activated appropriately at the time of receiving new information, leading to failure in integrating and remembering the new information. As we shall see in the next section, appropriate support for knowledge activation may be particularly important in children because of the immaturity of the neurocognitive mechanisms supporting the interactions between prior knowledge and memory processing.

Developmental differences in the cognitive effects of prior knowledge on memory processing

Baltes and colleagues distinguished between the mechanics and the pragmatics of cognition, and postulated dissociable lifespan trajectories in these two aspects of cognition (Baltes, Lindenberger, \& Staudinger, 2006; see also Craik \& Bialystok, 2006). The mechanics of cognition refer to basic aspects of information processing, such as episodic memory, which are closely associated to the developmental status of the brain and typically found to rise steeply during childhood (see review on the episodic memory domain in Shing, Werkle-Bergner, Brehmer, Mueller, Li, \& Lindenberger, 2010). The pragmatics of 
cognition refer to culture-based bodies of knowledge. Developmental changes in this component are usually induced in individuals over the course of socialization (Lindenberger, 2001). Socialization events can be universal (e.g., mother-child bonding), normative (e.g., formal schooling), or person-specific (e.g., specialized knowledge driven by personal interests). In light of the time needed to invest into knowledge acquisition, it is not surprising that cognitive pragmatics, such as knowledge of vocabulary, continue to grow well into adulthood (Li et al., 2004).

Knowledge increases dramatically during childhood, and therefore its significance for memory development has been investigated extensively (see review by Bjorklund, 1987). Indeed, numerous studies have demonstrated that the quantity and complexity of relevant knowledge structures affect how well information is understood and remembered. In situations in which children have expert knowledge, they can outperform non-expert young adults and reach performance levels equivalent to those of experts (Chi, 1978; Schneider et al., 1993).

This early work laid the foundation for our understanding of the beneficial effects of increasing knowledge availability on memory development (cf. Bjorklund, 1987). However, two important issues remain. First, it is crucial to point out that, according to a slightly different body of literature on knowledge and suggestibility, children's memory accuracy can be enhanced or undermined by general knowledge (see also Farrar \& Goodman, 1990; Sloutsky \& Fisher, 2004). Second, to fully understand the effects of knowledge on memory, it is important to distinguish the availability of prior knowledge from its accessibility and use (Brod et al., 2013). We elaborate on these points in the following. 
On the issue of memory disadvantage due to knowledge, Elischberger (2005) showed that academic knowledge relating to the content of stories told to children led to a decrease in knowledge-inconsistent errors, but also an increase in knowledge-consistent errors. Furthermore, when erroneous information was later presented, children tended to refute misinformation that contradicted their academic knowledge, but were also more likely to report misinformation that was consistent with their knowledge. These findings are consistent with the literature on the so-called memory congruency effect, which denotes a memory advantage for schema-congruent as opposed to schema-incongruent new information. This is because congruent information can be integrated more easily through elaborate encoding (Bein et al., 2015; Craik \& Tulving, 1975). However, the advantage of congruent new information plays out as a disadvantage of incongruent new information, which is often ignored (Alba \& Hasher, 1983). Therefore, despite benefits of knowledge availability, we need to be aware that prior knowledge introduces a bias into memory processing that can also lead to memory errors. In particular, when partial or wrongly applied knowledge is activated during the processing of new information, it can lead to biased processing and misconceptions (see also Greenhoot, 2000).

On the issue of availability vs. accessibility, we argue that to fully understand the commonalities as well as differences in effects of prior knowledge on memory in an agecomparative setting, we consider it necessary to distinguish the availability of prior knowledge from its accessibility and use (Brod et al., 2013). This is because age is often confounded with amount of knowledge. This converges with the increase of the memory congruency effect across childhood in accordance with the rise in children's knowledge (Stangor \& McMillan, 1992). Given this, using experimentally induced knowledge can be 
advantageous for comparisons between age groups because it allows for careful monitoring of the knowledge available to the participants, circumventing problems of comparability in studies involving previous expertise. We will return to this point further below.

Neurocognitive mechanisms underlying the effects of prior knowledge on memory processing

Neuroimaging research, particularly work involving functional magnetic resonance imaging (fMRI), has identified several key brain regions that are involved in memory processing of new information in relation to prior knowledge. In a recent review (Brod et al., 2013), we focused on distinguishing the roles of the lateral and medial prefrontal cortices (PFC) in this process. Lateral parts of the PFC, particularly the inferior frontal gyrus, have been shown to be involved in memory processes related to knowledge use, such as semantic elaboration, that are beneficial for memory success (e.g., Badre \& Wagner, 2007; Blumenfeld \& Ranganath, 2007; Staresina, Gray, \& Davachi, 2009; Wagner et al., 1998). Furthermore, a more dorsal part of the lateral PFC contributes to successful formation of associative memories, possibly due to its role in forming relationships between items and in exerting control on memory retrieval (Murray \& Ranganath, 2007).

While the lateral PFC may be engaged when new information is being transformed, organized, or elaborated by making use of prior knowledge, the medial part of the PFC seems to be involved in detecting fit or congruency between new information and prior knowledge during encoding and retrieval (Hebscher \& Gilboa, 2016; Moscovitch \& Winocur, 2002; Preston \& Eichenbaum, 2013; van Kesteren et al., 2012). It is further 
assumed that the medial PFC biases the involvement of the hippocampus in memory processing. That is, with strong congruency, binding processes (important when linking units of information together) are suppressed in the hippocampus, and connections between the new information and existing schemas represented in the neocortex are directly established (Nieuwenhuis \& Takashima, 2011). However, direct evidence for this notion remains to be presented. In a similar vein, but coming from a slightly different perspective, namely the examination of consolidation, Takashima and colleagues (2006) found that, across a three-month period after initial encoding, hippocampal activation decreased and activation of the medial PFC increased to achieve successful recognition of pictures. This finding suggests that the medial PFC takes over linking functions from the hippocampus to retrieve consolidated memories (see also Yamashita et al., 2009). Therefore, across several stages of memory processing, the interplay between medial PFC and hippocampus seems to be modulated by prior knowledge.

In a recent study, we directly contrasted the contributions of lateral PFC and medial PFC to schema-related memory retrieval by using a newly developed paradigm that experimentally induced new knowledge in participants (Brod et al., 2015). In line with the aforementioned hypotheses about the different roles of the two regions, we found that the medial PFC was associated with the successful retrieval of schema-congruent information. The lateral PFC was associated with the successful retrieval of schema-incongruent information, which requires recollection of the specific context of the encoding situation and overcoming biases from prior knowledge. These findings square well with a recent study by Schlichting and colleagues (2015), showing that an area in the medial PFC is involved in generalization across episodes, whereas a lateral PFC region contributed to the 
separation of episodes.

Interestingly, the role of prior knowledge has also been implicated in memory consolidation (e.g., Hennies et al., 2016). Consolidation refers to a process during which new and initially labile memories (presumably formed by the hippocampus) are transformed into more stable representations that become integrated into the pre-existing knowledge network represented across the neocortex (Dudai, 2004; Dudai \& Morris, 2013). The hippocampus and neocortex are hence considered complementary learning systems (McClelland, McNaughton, \& O'Reilly, 1994). The general consensus is that the process of consolidation is slow. Wang and Morris (2010) later postulated, however, that knowledge structures can facilitate the assimilation of related new information, particularly by speeding up consolidation. Initial animal data support this notion. In particular, Tse and colleagues (2007) showed that, in rats trained to associate flavors with places (i.e., establishing prior knowledge), the removal of the entire hippocampus as early as 48 hours after learning new flavor-place associations fully spared memory, suggesting that the new memory representations were consolidated in the neocortex. Another important role of consolidation is to capture regularities across experiences, which depends on offline memory reactivation, recombination, and redistribution from hippocampus to neocortical sites, occurring preferably during sleep (Diekelmann \& Born, 2010). Considering that this consolidation process might be the core force of knowledge accumulation, the way in which prior knowledge modulates consolidation becomes an even more relevant issue for educators.

Developmental differences in the neurocognitive effects of prior knowledge on memory 


\section{processing}

Brain regions that underpin memory differ with respect to their developmental trajectories (Ghetti \& Bunge, 2012; Ofen, 2012; Shing et al., 2010). However, the ways in which memory regions and networks are modulated by prior knowledge across development are not well known. Evidence for an age-related increase in the use of prior knowledge for memory has been provided by an fMRI study in which words were presented together with colors, and the word-color combination was either plausible or implausible (Maril et al., 2011). Both children (aged 8-11 years) and young adults remembered the plausible combinations better than the implausible ones. However, this effect was associated with more extensive posterior brain activation (i.e., right occipital cortex) in the children, and more extensive anterior brain activation (lateral PFC and parietal regions) in the young adults. These observations were taken to reflect a shift from perceptual-based processing in children to more conceptual-semantic and controlled encoding processing in the adults (Maril et al., 2011).

Another study by Paz-Alonso and colleagues (2008) used the Deese-RoedigerMcDermott paradigm to show that increases in false alarm rates for critical lures across middle childhood are related to enhanced activation in the ventrolateral PFC, which was assumed to reflect an increased use of semantic knowledge for memory. These findings converge with evidence that the lateral PFC contributes heavily to memory improvements across childhood (Ofen, 2012; Shing et al., 2010). In part, this is due to facilitation of the utilization of strategic operations that make use of prior knowledge to process new information. However, neither the study from Maril et al. or Paz-Alonso et al. could rule out the possibility that the age-related differences observed in brain activation patterns were 
due to age-related differences in knowledge about the stimulus material.

In a recent study (Brod et al., in press), we tackled the question of whether agerelated differences in the neural mechanisms underlying the effects of prior knowledge on memory remain even if the amount of available knowledge is equalized for children and younger adults. Age-independent knowledge structures were ensured via experimental induction of new knowledge, which then served as prior knowledge for the memory task. Preliminary evidence from this study suggests that, despite similar levels of memory performance, medial PFC activation was reduced in children as compared to young adults when successfully retrieving events that were congruent with prior knowledge. Furthermore, there was a positive correlation between the children's age (ranging from 8 to 12 years) and medial PFC activity, suggesting that children in this age group are undergoing a transition in their memory system. On the other hand, when successfully retrieving memory that was incongruent with prior knowledge, children showed stronger hippocampus activation than young adults.

Taken together, we think that these findings suggest an age-related shift from hippocampal binding to prefrontal schema processing in memory retrieval across middle childhood, and that this occurs independently of age-related differences in knowledge availability. Below we discuss how these insights could be relevant to education.

\section{Potential implications for educational settings}

Our review of findings on neurocognitive mechanisms that support the encoding, consolidation, and retrieval of new information against the backdrop of prior knowledge suggests several implications for educational settings. We recognize that findings from 
experimental studies, in particular those taking place in an MRI scanner, do not easily apply to real-world settings due to the obvious vast differences in context (laboratory vs. classroom) and for methodological reasons (e.g., sample selection bias and differences in task complexity). Therefore, our main goal here is to highlight gaps between recent insights from cognitive neuroscience and potential implications in educational settings, calling for further investigation to examine the relevance of cognitive neuroscience findings on children's learning in real world. Given our focus on prefrontal immaturity and hippocampal processing in development, the following implications are most relevant to learners in elementary and middle school age years.

First, the relative immaturity of PFC (particularly the lateral parts) in schoolchildren seems to disadvantage them in making use of prior knowledge, even when that knowledge is clearly available in the memory system. This underscores the need to structure learning environments adaptively to make up for this shortcoming. For example, children could be induced to reactivate appropriate prior knowledge before new information is presented and then prompted to make connections between the new information and their knowledge.

This point is consistent with existing insights from educational psychology/instructional science that point to the beneficial effect of knowledge activation in classroom settings (e.g., Lucariello et al., 2016; Spires \& Donley, 1998). However, we must emphasize that the structuring of the learning environment needs to be adapted to the individual developmental status of the learners (not just to their chronological age or school year) because of the protracted development of the PFC and the individual differences therein. Indeed, age-differential effects of prior knowledge activation have been 
observed before (e.g., Gurlitt \& Renkl, 2008; Hasselhorn, 1990). Gurlitt and Renkl (2008) compared prior knowledge activation in high school students and university students on a concept-mapping science task. High school students profited more from a "high-coherent" prior knowledge activation, which provides a highly structured learning environment, whereas university students profited more from a low-coherent activation, which requires more self-organization of the learning material.

Therefore, learners, depending on their developmental status (i.e. structural or functional integrity of PFC), may need varying amounts of support to activate available prior knowledge in their system in order to process new information in such a way that maximizes durability of memory representations formed. At this point it is difficult to provide more exact recommendation in terms of what the varying levels of support should entail, other than the rule of thumb of the younger the learners, the more concrete support is needed. This is a knowledge gap that needs to be filled in future studies, combining instructional science and neuroimaging levels of analysis.

Second, beyond changes in regional activation, connectivity between the hippocampus and neocortical brain regions is implicated in the support of memory-based problem solving during cognitive development. In this light, connectivity surrounding the hippocampus may affect knowledge-related processing when children solve problems in educational settings. This view is in line with Johnson's (2001) perspective on interactive specialization that it is the refinement of connectivity between regions, rather than within a single region, that is important for the onset of a new behavioral ability. Memory-based problem solving supports children to transition away from using manipulatives (e.g. counting finger) to using retrieval as means of solving arithmetic problems (Carr \& 
Alexeev, 2011). Providing the neural correlates of such transition, Qin and colleagues (2014) found that increases in functional connectivity between the hippocampus and several parts of the neocortex, including prefrontal, anterior temporal, and parietal cortex, predicted long-term improvement in the use of a retrieval-based strategy (rather than counting) to solve basic arithmetic problems. Structurally, white matter tracts between the hippocampus and PFC (i.e., the uncinate fasciculus) mature more slowly than connections between the hippocampus and subcortical structures (i.e., the fornix; e.g., Lebel et al., 2012). Structural changes in these tracts may have implications for the reorganization of networks surrounding the hippocampus, in light of developmental shifts from short- to long-range connectivity of functional networks (e.g., Fair et al., 2007).

In general, age-related changes in structural and functional connectivity between the mediotemporal lobe and neocortical regions are only beginning to be elucidated. The implications of these changes for memory development are not yet well understood (cf. Wendelken et al., 2015). On the other hand, the cognitive neuroscience literature provides good evidence that the connectivity between hippocampus, medial PFC, and temporal regions are important for the support of the effects of prior knowledge on memory processing (see van Kesteren et al., 2012). Therefore, it is conceivable that age-related changes in the integrity of connectivity surrounding the hippocampus may constrain or foster processes of learning, consolidation, and application of knowledge when children solve problems in educational settings. This postulation needs to be tested with empirical data.

Finally, it has been shown that the strong hippocampus-bound memory processing in children allows them to form novel representations of arbitrary units of information 
with relative ease, especially as compared to older adults (Shing, Werkle-Bergner, Li, \& Lindenberger, 2008). This great capacity for hippocampus-dependent memory formation coincides with longer and deeper sleep in children, which is critical for the redistribution of these newly formed memories from hippocampus to neocortical sites (e.g., Wilhelm, PrehnKristensen, \& Born, 2012). This redistribution can be enhanced significantly when applicable schemas exist (Tse et al., 2007).

Indeed, an emerging body of evidence suggests that sleep plays an important role in the consolidation of memories in the early years of life (Seehagen, Konrad, Herbert, \& Schneider, 2015; Henderson, Weighall, Brown, \& Gaskell, 2012). Also, mechanisms for sleep-dependent memory consolidation during development do not appear to be entirely different from those in adults. Notably, Wilhelm and colleagues (2013) found that, when sleep followed implicit training on a motor sequence, children showed greater gains in explicit sequence knowledge after sleep than adults. This can be linked to their higher proportion of phases of slow-wave brain activity during sleep. Slow-wave sleep is a sleep stage that causally contributes to the consolidation of memories (Marshall \& Born, 2006; Rasch, Büchel, Gais, \& Born, 2007). Therefore, longer and deeper slow-wave sleep in children may produce a superior strengthening of hippocampus-dependent declarative memories, possibly making up for their less extensive knowledge base. In this regard, it is conceivable that sleep may play an even more important role for children's memory than for adults'. This notion is in line with recent work by Darby and Sloutsky (2015a), showing that young children are more vulnerable to catastrophic levels of memory interference than adults, with new learning dramatically attenuating memory for previously acquired knowledge. However, by having a longer delay between learning and testing (in this case, 
48 hours), children's memory can be improved and interferences eliminated. This is presumably due to the extra time available for sleep-induced consolidation (Darby \& Sloutsky, 2015b).

Therefore, it is imperative that educators have an understanding of the significance of sleep for memory as well as for cognitive functioning in general. Taking a step further, sleep could potentially be integrated into teaching and learning programs of specific domains, such as with targeted memory reactivation during slow-wave sleep for language learning (Schreiner \& Rasch, 2016). At a minimum, educators and parents should be well informed about factors that can promote or impede children's and adolescents' sleep quality (e.g., Adolescent Sleep Working Group, Committee on Adolescence, and Council on School Health, 2014, for recommendations to delay middle and high school start times).

In sum, the acquisition of academic knowledge represents only one of various educational goals. Ultimately we want to teach children to become individuals who can independently identify overlaps, but also gaps and contradictions in their knowledge in relation to the ever-changing world (i.e. to be metacognitive about their own knowledge; Kuhn, 2000, 2001). Having a well-grounded understanding of how the developing mind and brain acquires, consolidates, and applies its knowledge structure is highly important and relevant in the process of achieving this ultimate goal. 


\section{References}

Adolescent Sleep Working Group, Committee on Adolescence, and Council on School Health (2014). School start times for adolescents. Pediatrics, 134, 642-649.

Alba, J. W., \& Hasher, L. (1983). Is memory schematic? Psychological Bulletin, 93(2), 203231.

Badre, D., \& Wagner, A. D. (2007). Left ventrolateral prefrontal cortex and the cognitive control of memory. Neuropsychologia, 45(13), 2883-2901.

Baltes, P. B., Lindenberger, U., \& Staudinger, U. M. (2006). Lifespan theory in developmental psychology. In W. Damon \& R. M. Lerner (Eds.), Handbook of child psychology: Vol. 1. Theoretical models of human development (6th ed., pp. 569-664). New York: Wiley.

Bein, O., Livneh, N., Reggev, N., Gilead, M., Goshen-Gottstein, Y., \& Maril, A. (2015). Delineating the effect of semantic congruency on episodic memory: The role of integration and relatedness. PloS One, 10(2): e0115624.

Bjorklund, D. F. (1987). How age changes in knowledge base contribute to the development of children's memory: An interpretive review. Developmental Review, 7(2), 93-130.

Blumenfeld, R. S., \& Ranganath, C. (2007). Prefrontal cortex and long-term memory encoding: An integrative review of findings from neuropsychology and neuroimaging. Neuroscientist, 13(3), 280-291.

Bransford, J., \& Johnson, M. (1972). Contextual prerequisites for understanding: Some investigators of comprehension and recall. Journal of Verbal Learning and Verbal Behavior, 11, 717-726. 
Brod, G., Werkle-Bergner, M., \& Shing, Y. L. (2013). The influence of prior knowledge on memory: A developmental cognitive neuroscience perspective. Frontiers in Behavioral Neuroscience, 7: 139.

Brod, G., Lindenberger, U., \& Shing, Y. L. (in press). Neural activation patterns during retrieval of schema-related memories: Differences and commonalities between children and adults. Developmental Science.

Brod, G., Lindenberger, U., Werkle-Bergner, M., \& Shing, Y. L. (2015). Differences in the neural signature of remembering schema-congruent and schema-incongruent events. NeuroImage, 117, 358-366.

Carey, S. (2000). Science education as conceptual change. Journal of Applied Developmental Psychology, 21(1), 13-19.

Carr, M. \& Alexeev, N. (2011). Fluency, accuracy, and gender predict developmental trajectories of arithmetic strategies. Journal of Educational Psychology, 103(3), 617631.

Chi, M. T. H. (1978). Knowledge structures and memory development. In R. S. Siegler (Ed.), Children's thinking: What develops? (Vol. 1, pp. 75-96). London: Routledge.

Craik, F. I. M., \& Bialystok, E. (2006). Cognition through the lifespan : Mechanisms of change. Trends in Cognitive Sciences, 10(3), 131-138.

Craik, F. I. M., \& Lockhart, R. S. (1972). Levels of processing: A framework for memory research. Journal of Verbal Learning and Verbal Behavior, 11(6), 671-684.

Craik, F. I., \& Tulving, E. (1975). Depth of processing and the retention of words in episodic memory. Journal of Experimental Psychology: General, 104(3), 268-294. 
Darby, K. P., \& Sloutsky, V. M. (2015a). The cost of learning: Interference effects in memory development. Journal of Experimental Psychology: General, 144, 410-431.

Darby, K. P., \& Sloutsky, V. M. (2015b). When delays improve memory: Stabilizing memory in children may require time. Psychological Science, 26(12), 1937-1946.

Diekelmann, S., \& Born, J. (2010). The memory function of sleep. Nature Reviews. Neuroscience, 11(2), 114-126.

diSessa, A. A. (2006). A history of conceptual change research: Threads and fault lines. In R. K. Sawyer (Ed.), The Cambridge handbook of the learning sciences (pp. 265-281). New York: Cambridge University Press.

Dudai, Y. (2004). The neurobiology of consolidations, or, how stable is the engram? Annual Review of Psychology, 55, 51-86.

Dudai, Y., \& Morris, R. G. M. (2013). Memorable trends. Neuron, 80, 742-750.

Elischberger, H. B. (2005). The effects of prior knowledge on children's memory and suggestibility. Journal of Experimental Child Psychology, 92(3), 247-275.

Fair, D. A., Dosenbach, N. U. F., Church, J. A., Cohen, A. L., Brahmbhatt, S., Miezin, F. M., \& Schlaggar, B. L. (2007). Development of distinct control networks through segregation and integration. Proceedings of the National Academy of Sciences of the United States of America, 104, 13507-13512.

Farrar, M. J., \& Goodman, G. S. (1990). Developmental differences in the relation between scripts and episodic memories: Do they exist? In R. Fivush \& J. A. Hudson (Eds.), Knowing and remembering in young children (pp. 30-64). New York: Cambridge University Press. 
Ghetti, S., \& Bunge, S. A. (2012). Neural changes underlying the development of episodic memory during middle childhood. Developmental Cognitive Neuroscience, 2(4), 381395.

Ghosh, V. E., \& Gilboa, A. (2014). What is a memory schema? A historical perspective on current neuroscience literature. Neuropsychologia, 53, 104-114.

Greenhoot, A. F. (2000). Remembering and understanding: The effects of changes in underlying knowledge on children's recollections. Child Development, 71(5), 13091328.

Gurlitt, J., \& Renkl, A. (2008). Are high-coherent concept maps better for prior knowledge activation? Differential effects of concept mapping tasks for high school versus university students. Journal of Computer-Assisted Learning, 24, 407-419.

Hardy, I., Jonen, A., Moeller, K., \& Stern, E. (2006). Effects of instructional support within constructivist learning environments for elementary school students' understanding of "floating and sinking." Journal of Educational Psychology, 98(2), 307-326.

Hasselhorn, M. (1990). The emergence of strategic knowledge activation in categorical clustering during retrieval. Journal of Experimental Child Psychology, 50(1), 59-80.

Hebscher, M., \& Gilboa, A. (2016). A boost of confidence: The role of the ventromedial prefrontal cortex in memory, decision-making, and schemas. Neuropsychologia.

Henderson, L. M., Weighall, A. R., Brown, H., \& Gaskell, M. G. (2012). Consolidation of vocabulary is associated with sleep in children. Developmental Science, 15(5), 674687. 
Hennies, N., Ralph, M. A. L., Kempkes, M., Cousins, J. N., \& Lewis, P. A. (2016). Sleep Spindle Density Predicts the Effect of Prior Knowledge on Memory Consolidation. The Journal of Neuroscience, 36(13), 3799-3810.

Johnson, M. H. (2000). Functional brain development in infants: Elements of an interactive specialization framework. Child Development, 71, 75-81.

Kuhn, D. (2000). Metacognitive development. Current Directions in Psychological Science, $9(5), 178-181$.

Kuhn, D. (2001). How do people know? Psychological Science, 12(1), 1-8.

Lebel, C., Gee, M., Camicioli, R., Wieler, M., Martin, W., \& Beaulieu, C. (2012). Diffusion tensor imaging of white matter tract evolution over the lifespan. NeuroImage, 60(1), 340352.

Li, S.-C., Lindenberger, U., Hommel, B., Aschersleben, G., Prinz, W., \& Baltes, P. B. (2004). Transformation in the couplings among intellectual abilities and constituent cognitive processes across the life span. Psychological Science, 15(3), 155-163.

Lindenberger, U. (2001). Lifespan theories of cognitive development. In N. J. Smelser \& P. B. Baltes (Eds.), International encyclopedia of the social and behavioral sciences (pp. 8848-8854). Oxford, UK: Elsevier Science.

Lucariello, J. M., Nastasi, B. K., Anderman, E. M., Dwyer, C., Ormiston, H., \& Skiba, R. (2016). Science supports education: The behavioral research base for psychology's top 20 principles for enhancing teaching and learning. Mind, Brain, and Education, 10(1), 5567. 
Maril, A., Avital, R., Reggev, N., Zuckerman, M., Sadeh, T., Ben Sira, L., \& Livneh, N. (2011). Event congruency and episodic encoding: A developmental fMRI study. Neuropsychologia, 49(11), 3036-3045.

Marshall, L., \& Born, J. (2007). The contribution of sleep to hippocampus-dependent memory consolidation. Trends in Cognitive Science, 11, 442-450.

McClelland, J. L., McNaughton, B. L., \& O’Reilly, R. (1994). Why there are complementary learning systems in the hippocampus and neocortex: Insights from the successes and failures of connectionist models of learning and memory. Psychological Review, 102(3), 419-457.

Moscovitch, M., \& Craik, F. I. M. (1976). Depth of processing, retrieval cues, and uniqueness of encoding as factors in recall. Journal of Verbal Learning and Verbal Behavior, 15, 447-458.

Moscovitch, M., \& Winocur, G. (2002). The frontal cortex and working with memory. In D. T. Stuss \& R. T. Knight (Eds.), Principles of frontal lobe function (pp. 188-209). New York: Oxford University Press.

Murray, L. J., \& Ranganath, C. (2007). The dorsolateral prefrontal cortex contributes to successful relational memory encoding. Journal of Neuroscience, 27(20), 5515-5522.

Nieuwenhuis, I. L. C., \& Takashima, A. (2011). The role of the ventromedial prefrontal cortex in memory consolidation. Behavioural Brain Research, 218(2), 325-334.

Ofen, N. (2012). The development of neural correlates for memory formation. Neuroscience \& Biobehavioral Reviews, 36(7), 1708-1717. 
Paz-Alonso, P. M., Ghetti, S., Donohue, S. E., Goodman, G. S., \& Bunge, S. A. (2008).

Neurodevelopmental correlates of true and false recognition. Cerebral Cortex, 18(9), $2208-2216$.

Piaget, J. (1926). The language and thought of the child. London: Routledge \& Kegan Paul.

Piaget, J. (1952). The origins of intelligence in children. New York: International Universities Press.

Preston, A., \& Eichenbaum, H. (2013). Interplay of hippocampus and prefrontal cortex in memory. Current Biology, 23(17), R764-773.

Qin, S., Cho, S., Chen, T., Rosenberg-Lee, M., Geary, D. C., \& Menon, V. (2014). Hippocampalneocortical functional reorganization underlies children's cognitive development. Nature Neuroscience, 17, 1263-1269.

Rasch, B., Büchel, C., Gais, S., \& Born, J. (2007). Odor cues during slow-wave sleep prompt declarative memory consolidation. Science, 315(5817), 1426-1429.

Schlichting, M. L., Mumford, J. A., \& Preston, A. R. (2015). Learning-related representational changes reveal dissociable integration and separation signatures in the hippocampus and prefrontal cortex. Nature Communications, 6: 8151.

Schneider, W., Gruber, H., Gold, A., \& Opwis, K. (1993). Chess expertise and memory for chess positions in children and adults. Journal of Experimental Child Psychology, 56(3), 328-349.

Seehagen, S., Konrad, C., Herbert, J. S., \& Schneider, S. (2015). Timely sleep facilitates declarative memory consolidation in infants. Proceedings of the National Academy of Sciences of the United States of America, 112(5), 1625-1629. 
Shing, Y. L., Werkle-Bergner, M., Brehmer, Y., Müller, V., Li, S.-C., \& Lindenberger, U. (2010). Episodic memory across the lifespan: The contributions of associative and strategic components. Neuroscience \& Biobehavioral Reviews, 34(7), 1080-1091.

Shing, Y. L., Werkle-Bergner, M., Li, S.-C., \& Lindenberger, U. (2008). Associative and strategic components of episodic memory: A lifespan dissociation. Journal of Experimental Psychology: General, 137(3), 495-513.

Sloutsky, V. M., \& Fisher, A. V. (2004). When development and learning decrease memory. Psychological Science, 15(8), 553-558.

Spires, H. A., \& Donley, J. (1998). Prior knowledge activation: Inducing engagement with informational texts. Journal of Educational Psychology, 90(2), 249-260.

Stangor, C., \& McMillan, D. (1992). Memory for expectancy-congruent and expectancyincongruent information: A review of the social and social developmental literatures. Psychological Bulletin, 111(1), 42-61.

Staresina, B. P., Gray, J. C., \& Davachi, L. (2009). Event congruency enhances episodic memory encoding through semantic elaboration and relational binding. Cerebral Cortex, 19(5), 1198-1207.

Takashima, A., Petersson, K. M., Rutters, F., Tendolkar, I., Jensen, O., Zwarts, M. J., ... Fernández, G. (2006). Declarative memory consolidation in humans: A prospective functional magnetic resonance imaging study. Proceedings of the National Academy of Sciences of the United States of America, 103(3), 756-761.

Tse, D., Langston, R. F., Kakeyama, M., Bethus, I., Spooner, P. A, Wood, E. R., ... Morris, R. G. M. (2007). Schemas and memory consolidation. Science, 316(5821), 76-82. 
Van den Broek, P., \& Kendeou, P. (2008). Cognitive processes in comprehension of science texts : The role of co-activation in confronting misconceptions. Applied Cognitive Psychology, 22(3), 335-351.

van Kesteren, M. T. R., Ruiter, D. J., Fernández, G., \& Henson, R. N. (2012). How schema and novelty augment memory formation. Trends in Neurosciences, 35(4), 211-219.

Vosniadou, S., \& Brewer, W. F. (1992). Mental models of the earth: A study of conceptual change in childhood. Cognitive Psychology, 24(4), 535-585.

Vosniadou, S., \& Brewer, W. F. (1994). Mental models of the day/night cycle. Cognitive Science, 18(1), 123-183.

Vosniadou, S., Ioannides, C., Dimitrakopoulou, A., \& Papademetriou, E. (2001). Designing learning environments to promote conceptual change in science. Learning and Instruction, 11, 381-419.

Vosniadou, S., Skopeliti, I., \& Ikospentaki, K. (2004). Modes of knowing and ways of reasoning in elementary astronomy. Cognitive Development, 19(2), 203-222.

Wagner, A. D., Schacter, D. L., Rotte, M., Koutstaal, W., Maril, A., Dale, A., ... Buckner, R. L. (1998). Building memories: Remembering and forgetting of verbal experiences as predicted by brain activity. Science, 281(5380), 1188-1191.

Wang, S.-H., \& Morris, R. G. M. (2010). Hippocampal-neocortical interactions in memory formation, consolidation, and reconsolidation. Annual Review of Psychology, 61, 49$79, \mathrm{C} 1-4$.

Wendelken, C., Lee, J. K., Pospisil, J., Sastre, M., Ross, J. M., Bunge, S. A., \& Ghetti, S. (2015). White matter tracts connected to the medial temporal lobe support the development of mnemonic control. Cerebral Cortex, 25(9), 2574-2583. 
Wilhelm, I., Prehn-Kristensen, A., \& Born, J. (2012). Sleep-dependent memory consolidation: What can be learnt from children? Neuroscience \& Biobehavioral Reviews, 36(7), 1718-1728

Wilhelm, I., Rose, M., Imhof, K. I., Rasch, B., Büchel, C., \& Born, J. (2013). The sleeping child outplays the adult's capacity to convert implicit into explicit knowledge. Nature Neuroscience, 16(4), 391-393.

Yamashita, K., Hirose, S., Kunimatsu, A., Aoki, S., Chikazoe, J., Jimura, K., ... Konishi, S. (2009). Formation of long-term memory representation in human temporal cortex related to pictorial paired associates. Journal of Neuroscience, 29(33), 10335-10340. 